\title{
Evaluation of Smart Phone Applications Accessibility for Blind Users
}

\author{
Nimra Sultan \\ Department of \\ Computer Science \\ and \\ Information \\ Technology, \\ Jinnah University for \\ Women \\ 5-C, Nazimabad, \\ Karachi, Pakistan
}

\author{
Kainat Siddiq \\ Department of \\ Computer Science \\ and \\ Information \\ Technology, \\ Jinnah University for \\ Women \\ 5-C, Nazimabad, \\ Karachi, Pakistan
}

\author{
Tabia Rashid \\ Department of \\ Computer Science \\ and \\ Information \\ Technology, \\ Jinnah University for \\ Women \\ 5-C, Nazimabad, \\ Karachi, Pakistan
}

\author{
Maria Farooque \\ Department of \\ Computer Science \\ and \\ Information \\ Technology, \\ Jinnah University for \\ Women \\ 5-C, Nazimabad, \\ Karachi, Pakistan
}

\begin{abstract}
Smart phones are becoming ubiquitous in this globalization era. Number of recent studies focused on web accessibility for blind users and also tries to address problems faced by the vision impaired people. However there is a prominent lack of research on smart phone accessibility for such people. The objective of this research is to review the accessibility of smart phone's features and applications by the visually impaired people. This study highlights the problems faced by such people in accessing the android smart phones. Hypothetical analysis was conducted through survey and different task-sets were designed to evaluate open-source android phones accessibility applications. Some visually impaired users performed task-set to analyze the smart phone usability. The evaluation takes place on the basis of Nielson's design principles. The results conclude that the recent android phone applications still do not meet the requirements and challenges faced by the visually impaired people. Therefore this research recommends designers to build an easily accessible application.
\end{abstract}

\section{Keywords}

Accessibility, usability, smart phones, visually impaired, android applications

\section{INTRODUCTION}

Today smart phone usage is common among people of almost all the ages and the emergence of smart phones and devices have very much influence in their daily activities. People are getting habitual of it. However there are some people who are physically challenged and needs special measures and devices to overcome their disability and merge themselves in the society. Although technology is increasing its potential level, therefore accessibility issues are almost resolved for a routine user; however smart phones are still inaccessible to visually impaired people.

Most blind people use Symbian phones for their daily activities as they don't feel comfortable with touch screens. In Pakistan, most of the blind people are still not using smart phones, as survey result shows that $80 \%$ students use symbian phones. $20 \%$ who uses smart phones still face difficulty to access smart phones accurately [1]. Market leading cellular companies like Apple, Samsung, and HTC have reached the height of success in designing smart phones for able people, but they are failing to impose the concept of "Universal
Design"[Thompson et al. 2002 ][2]. Although the developers specially care about the accessibility issues for visually impaired and They try not to violate the design principles within accessibility issues, but they are not completely successful in providing the friendly interaction for blind users [3]

The main objective of this paper is to examine the accessibility of smart phone for blind. For this purpose 4 different open source android applications have been chosen and 10 blind students of IDA Rieu School and college in Pakistan has taken to accomplish the research, For this study, 5 hypotheses were assumed and evaluated with the help of different accessibility application

This study addresses the needs of visually impaired people concerning smart phones. Evaluation included how much they were comfortable with the smart phones and what difficulties were faced by them while using applications. This evaluation highlighted the usability issues faced by users. Heuristics evaluation was also performed on the basis of Nielson's design principles, to find the major or minor issues in apps. Furthermore recommendations are also provided in this research to fix the issues.

\section{RELATED WORK}

A number of researchers defined the accessibility of websites, touch screen phones and tablet for blind people. In Mexico, [Mata et al. 2011] [4], introduced a mobile navigation metro bus system for blinds and sighted peoples which located and focused on the passengers of metro bus. They developed an inexpensive mobile phone with GPS and other digital compass devices and their interaction was attained by Bluetooth communications. Audible user interface help to locate the directions and boarding gates of the station.

As product specification and quality is prejudiced the buyer's judgments. So for blind people, it is very difficult to buy goods itself from the store. [Jethjarurach et al.2014] [5] developed an application which supported the self-governing and excellence of life for the blinds. They suggested using the application that has ability in photo taking with smart phones. In this research paper, they presented a methodology to develop a barcode reader application using smart phones which vocalized the specifications and captured the images to help the blind for procurement goods. 
[Cesarano et al.2007][6] proposed that web contents to any civilian or even the disable people is a major concern. W3C also proposed the guidelines for web developers to make the web content available, but it is deplorable that blind people are not absolutely used the website contents. They presented an approach that vigorously converting the web pages into aural web pages and provide a heuristics techniques to enhance the usability of blind users.

Another article, [Khan et al.2013] [7] affirmed on the news website accessibility for blind users and estimated the problems faced by the blind users using screen readers. They evaluated their work on local and international websites, using WCAG 2.0 tools. They conducted an experiment with blind peoples and stated that blind peoples are facing problems in both (local and international) websites, but international websites are better to accessible.

[Robest et al.2013] [8] Proposed platform which support the blind users to find the positions of the keypads? His objective is to support the blind users to use basic functionality of smart phone like make a call and send messages with accurately, easiness and restfully. He stated that for blind, games, applications will also be gradually developed. And these ideas can also be applied on tablets, and also permitting them to use the websites and news portals. Another application was designed by [Kane et al.2011 ][9], named as Slide Rule that uses gestures input and audio outputs to supports blind users to interact with the touch screens. In this article they conducted an experiment with 10 blind participants to compared Slide Rule and Pocket PC. And they showed that Slide Rule expressively faster to accessible by blind people.

[Green et al.2009][10] inspected the earlier studies about the SLIS (School of library and information sciences) and university websites, and figure these studies for individual with disabilities. The study examines the 12 top-ranked SLIS and their disability related programs. This study also survey to concluded disability circular contributions. The result showed maximum SLIS offering disability lessons and persons that were responsible for these sites were not well-informed. The study also stated that SLIS students were essentially skilled appropriate accessibility standards.

[Bray et al.2007][11] also examined the website accessibility for disable people, the study evaluated the accessibility homepages of middle schools. This study took 165 websites to evaluate for accessibility. A software program was calculated the errors of sites. Most sites have accessibility problems, and it should be given a high precedence for progress. But the good news is that the most of the errors were easily modified. The paper revealed a need to inspect and improve the accessibility of homepages for middle schools.

[Brandenburg et al.2013][12], reviewed the mobile accessibility for aphasia people, with encouraging and guiding further research. This study proposed the use of technology for non-rehabilitative people and also proposed the potential behaviors of speech pathology applications (apps), with the goal of improving research in this area. This study stated that more research is required in improving the accessibility and needed to work on mobile applications that help executing of aphasia.

Many researchers have worked on accessibility issues arose in smart phones applications but there is a still lack of study for this instance. The major contribution of this study is to evaluate the accessibility flaws in the below mentioned applications.

\section{ACCESSIBILITY APPLICATIONS FOR BLIND USERS}

Four different android free ware applications were selected. These applications provide accessibility to the blind users. The applications use the screen reader technology for audible feedback that assists the blind users to operate mobile.

\subsection{Blind Navigator:}

The app has 8 main functions: contacts, phone, messages, set alarm, calculator, color identifier, local eyes and services. The menu options are displayed in 4 rows and 2 columns help to understand in learning the menu selection for blind people. The app has its own screen reader. The option is select after a long press instead of double tapping. This app provides the basic functionality to use smart phones [13].

\subsection{Easy Phone for the blind:}

Through this app the users use the touch screen mobile phone and voice recognition systems to read messages, texts, notes and email. It also provides QWERTY keypad using slide touch feasibility that gives continuous feedback when the users contact the screen [14].

\subsection{Blind Launcher:}

This app is intended as a trouble-free way to use the basic functionality in their phones. The swapping functionality is used to perform the options of apps and users can select options by double tapping on it [15].

\subsection{Call dialer:}

This app is just a call dialer; the app is taken to evaluate the problems faced by blind while making calls [16].

\section{METHODOLOGY 4.1 Participants}

Ten visually impaired participants were selected from an educational institution, (IDA Rieu). The participants had minimal knowledge of English. They were familiar with JAWS and screen readers for accessing computers and mobile phone. Most of the participants were using symbian phones and had no experience of using smart phones.

\subsection{Experimental Study}

The evaluation was performed by using three Android phones from different brands and 4 different applications. Survey forms were prepared to note user feedback or recommendation with the listed factors in to conclude the overall result from participants. i) ease of use ii) learnability iii) no. of errors iv) efficiency v) understanding voice.

\subsection{Task Sets}

Following task sets were set to evaluate each application: a) Select option from the menu. b) Make a call. c) Compose a message. d) Read a message. e) Search a contact

\subsection{Procedure}

Participants performed each task individually using each application after demonstration. During this process, the survey forms were filled by activist. With these forms we evaluated their feedback by interviewing the users according 
to their comfort level. The task sets were assigned to analyze the estimated time taken to perform each task, the efficiency and the number of errors in performing the task.

\section{HYPOTHESIS}

Following hypothesis was assumed as per the facts

H1: Mostly visual impaired people use Symbian phones.

H2: Visually impaired will be more comfortable to use Smart phones with the help of applications than Symbian phones.

H3: Users will avoid switching to another screen reader and prefer the one they use regularly
H4: Such user will face difficulty while reading messages in Pakistan's native language phonetics.

H5; Applications will help in increasing number of smart phones users after proper awareness

\section{APPLICATION EVALUATION}

On the basis of Nielson's design the evaluation was measured on the following criteria: Positive findings, minor issues, major issue

\section{Table 1 Heuristics Evaluation}

\begin{tabular}{|c|c|c|c|c|}
\hline $\begin{array}{l}\text { HEURISTICS } \\
\text { EVALUATION }\end{array}$ & BLIND NAVIGATOR & $\begin{array}{l}\text { EASY PHONE FOR } \\
\text { BLIND }\end{array}$ & PHONE DIALER & BLIND LAUNCHER \\
\hline $\begin{array}{l}\text { Visibility of System } \\
\text { Status } \\
\text { TASKS } \\
\text { 1. Select option } \\
\text { from menu } \\
\text { 2. Make a call } \\
\text { 3. Compose } \\
\text { message } \\
\text { 4. Search contacts. }\end{array}$ & $\begin{array}{l}\text { Positive finding: } \\
\text { When option is selected it } \\
\text { gives feedback that the option } \\
\text { is selected. } \\
\text { Major issue: No continuous } \\
\text { feedback on sliding finger } \\
\text { upon the screen. When the } \\
\text { icon is pressed it provides } \\
\text { voice feedback of what the } \\
\text { option is. Due to it user get } \\
\text { difficulty in locating an option. } \\
\text { Minor issue: No feedback on } \\
\text { making a call. }\end{array}$ & $\begin{array}{l}\text { Positive finding: } \\
\text { Give feedback on sliding } \\
\text { finger anywhere on the } \\
\text { screen. } \\
\text { Major issue: Give } \\
\text { continuous feedback of } \\
\text { options, but not give the } \\
\text { feedback for the home } \\
\text { button. } \\
\text { Major issue: No } \\
\text { feedback for message } \\
\text { sent. }\end{array}$ & $\begin{array}{l}\text { Major issue: Not } \\
\text { continuous feedback. } \\
\text { Problem in locating } \\
\text { numbers, dial, button, clear } \\
\text { button on the screen. } \\
\text { Major issue: When the user } \\
\text { presses a number to enter it, } \\
\text { not gives feedback that the } \\
\text { number is selected (for } \\
\text { example "2 is selected"), } \\
\text { user confused whether it is } \\
\text { selected or not. }\end{array}$ & $\begin{array}{l}\text { Positive finding: } \\
\text { Give feedback of all options } \\
\text { when sliding a finger up to } \\
\text { down or down to up. } \\
\text { Minor issue: Give feedback } \\
\text { on swapping down or up on the } \\
\text { screen, but no feedback on } \\
\text { moving finger left to right. } \\
\text { Major issue: No feedback on } \\
\text { making patterns for dialing } \\
\text { numbers. }\end{array}$ \\
\hline \multicolumn{5}{|c|}{$\begin{array}{l}\text { Recommendation: Application should provide feedback on moving finger in all directions of the screen, and at every step which user } \\
\text { performed (if user select any option the system should give the message that this option is selected) }\end{array}$} \\
\hline $\begin{array}{l}\text { HEURISTICS } \\
\text { EVALUATION }\end{array}$ & BLIND NAVIGATOR & $\begin{array}{l}\text { EASY PHONE FOR } \\
\text { BLIND }\end{array}$ & PHONE DIALER & BLIND LAUNCHER \\
\hline $\begin{array}{l}\text { Match between } \\
\text { System and Real } \\
\text { World } \\
\text { TASKS } \\
\text { 1. Compose } \\
\text { message } \\
\text { 2. Search contacts. }\end{array}$ & $\begin{array}{l}\text { Positive Finding: } \\
\text { Speak words or phrases that a } \\
\text { user can understand. } \\
\text { Minor issue: } \mathrm{N} \text { is pronounced } \\
\text { as 'yen' while composing } \\
\text { messages or searches a contact } \\
\text { by typing the name. }\end{array}$ & $\begin{array}{l}\text { Positive Finding: } \\
\text { Speak words or phrases } \\
\text { that a user can } \\
\text { understand. }\end{array}$ & $\begin{array}{l}\text { Positive Finding: } \\
\text { Speak words or phrases that } \\
\text { a user can understand. } \\
\text { Numbers pronounced clearly } \\
\text { and are understandable. } \\
\text { No negative finding }\end{array}$ & $\begin{array}{l}\text { Positive Finding: } \\
\text { Speak words or phrases that a } \\
\text { user can understand. }\end{array}$ \\
\hline \multicolumn{5}{|c|}{ Recommendation: Use words or phrases, pronunciation that is understandable to users. } \\
\hline $\begin{array}{l}\begin{array}{l}\text { User Control } \\
\text { and Freedom }\end{array} \\
\text { For all tasks. }\end{array}$ & $\begin{array}{l}\text { Major issue: No home button } \\
\text { on the screen. }\end{array}$ & $\begin{array}{l}\text { Major issue: The home } \\
\text { button is on the top of } \\
\text { the screen, but when the } \\
\text { user takes his finger it } \\
\text { give no sound. }\end{array}$ & $\begin{array}{l}\text { This application is only a } \\
\text { phone dialer (only one } \\
\text { screen). No home button is } \\
\text { needed. }\end{array}$ & $\begin{array}{l}\text { Major issue: No home button } \\
\text { on the screen. }\end{array}$ \\
\hline \multicolumn{5}{|c|}{ Recommendation: Application should have a home button which user can locate easily for emergency exit. } \\
\hline ecommendation: & & & & he standards so that users will \\
\hline
\end{tabular}




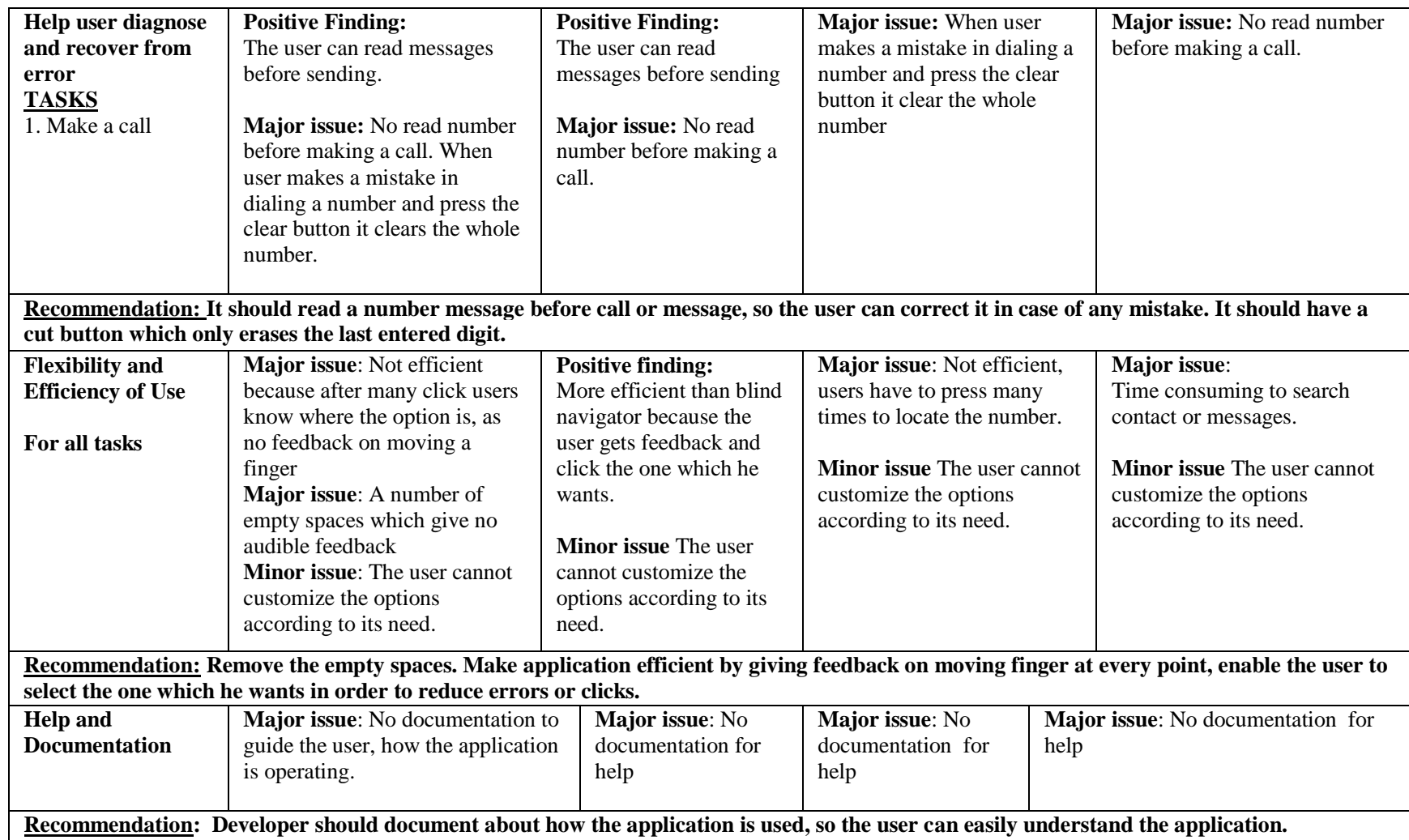

\section{DATA ANALYSIS}

The task sets were assigned to participants to analyze the usability of apps. The following criteria to calculate the task results are used: (i) got it quickly, (ii) got it eventually and (iii) needed help

Task \# 1: Select option for menu

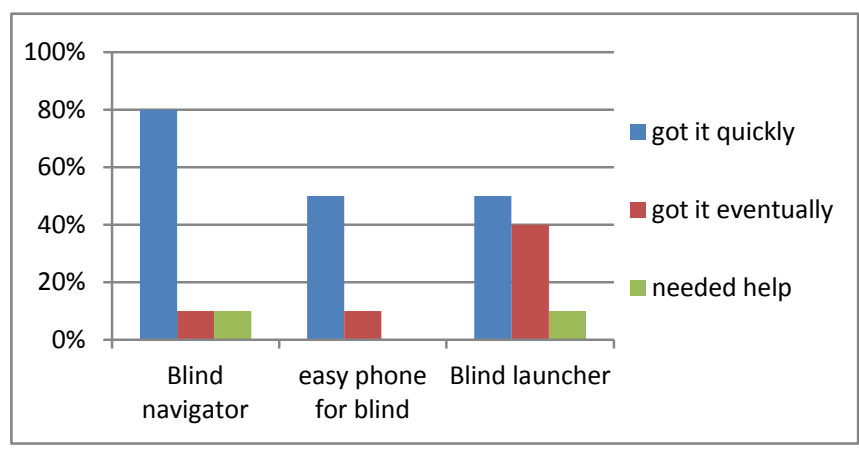

\section{Blind Navigator:}

Result: $80 \%$ of the participants easily performed the task and understood the application menu but $20 \%$ needed help.

Observation: It is observed that $80 \%$ easily learned the positions of the icons as there is no sliding feedback. On the other hand some users got difficulty.

\section{Blind Launcher:}

Result: The task was easily performed by the participants.

Observation: It is observed that the blind launcher menu task was easily performed because it has swapping option. The users swap down or up on the mobile screen to switch on the next option.

\section{Easy phone for Blind:}

Result: Participants faced many problems and took time to understand and complete the task.

Observation: It is observed that users were facing problems in menu selection because the menu options were so crammed to each other.

\section{Call Dialer:}

The feature is not available

\section{Task \# 2: Make a call}

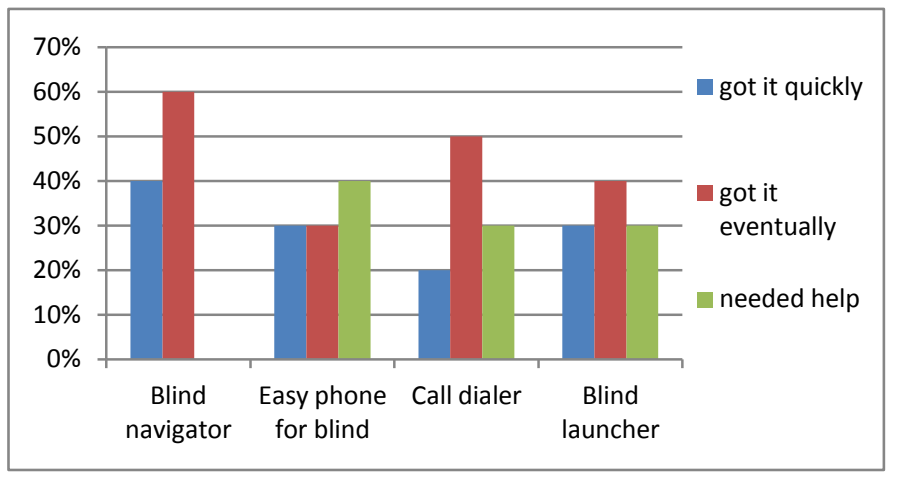

Call Dialer:

Result: Some of the participants completed the task but still many of the participants needed help.

Observation: It is observed that the buttons of call dialer are large in size so the users faced problems in locating the button. Users also were getting confused when they pressed a digit, and no feedback is provided that the digit is selected. They violated the Nielson's feedback principle. The call dialer has the clear button but it clears all the digits. 


\section{Blind Launcher:}

Result: Majority of the participants needed help and only fewer got it eventually to make a call. No participants perform the task quickly so the result shows the blind launcher have many flawed to dial a call.

Observation: It is observed that users get mystified while dialing a call because to dial a call, users have to make a pattern with their finger. It doesn't have any button. And it doesn't give any feedback.

\section{Blind Navigator:}

Result: Participants easily performed the task and understood the dialing option.

Observation: It is observed that users got it quickly. They took less time on dialing. Only problem in blind navigator is the clear button it clears all the digits. But once the users will get familiar, they will easily dial a call.

\section{Easy Phone for Blind:}

Result: In easy phone for blind, $30 \%$ users got it quickly to complete the task, $40 \%$ user got it eventually and $30 \%$ users needed help.

Observation: It is observed that users have got many problems to accomplish the task. The digits are horizontally display in a row, but the users are not familiar with it. Due to it they faced difficulty. It has one positive point; the delete button only deletes the last selected digit.

\section{Task\# 3: Compose Message}

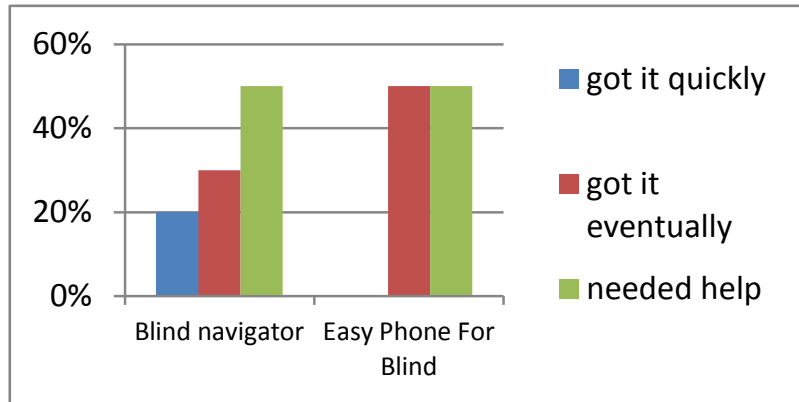

\section{Blind Navigator}

Result: Some users composed message easily while other faced difficulty in completing the task.

Observation: User got difficulty as they are not familiar with the QWERTY keypad and they faced trouble in locating the alphabets. The design principle of visibility of system status is violated in this task.

\section{Easy Phone for Blind}

Results: Users took less time on Easy Phone for Blind as compare to Blind Navigator.

Observation: Users were more comfortable because the keypad gives the continuous feedback of alphabets when they slide their finger on the keypad so they easily locate the alphabets.

\section{Blind Launcher}

The feature is not available.

\section{Call Dialer}

The feature is not available.
Task \# 4: Read a Message

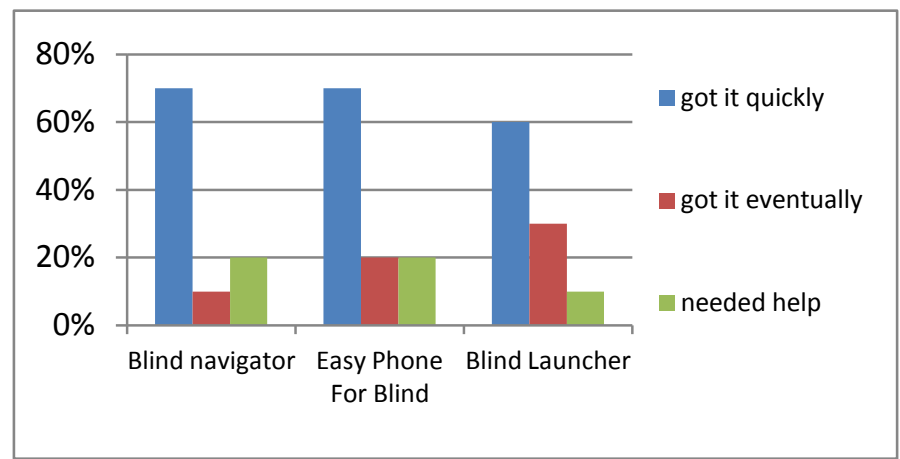

Blind Navigator, Easy Phone for blind and Blind Launcher:

Result: $70 \%$ participants understand the messages but some were not.

Observation: It is observed that the users easily understood the Basic English messages but some were facing problem to understand Pakistan's native language phonetics and the text written in short forms.

\section{Call Dialer:}

The feature is not available in call dialer.

\section{Task \# 5: Search Contacts}

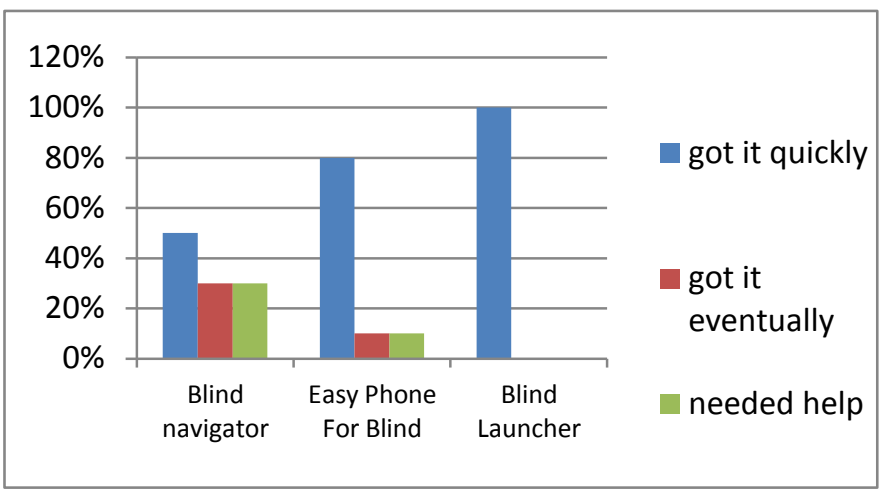

\section{Blind Navigator}

Results: Some users searched the contact quickly but some faced difficulty in completing the task.

Observation: Users faced difficulty because after selecting the contact page it gives no description. Two buttons are on the top i) list all contacts ii) search by name and the other area of the screen has empty white space. User pressed on all over the screen to locate the buttons as there is no feedback on sliding finger. The design principle of i) Visibility of System Status ii) flexibility and efficiency violates for this task

\section{Easy Phone for Blind}

Results: Users easily searched contact as compared to Blind Navigator.

Observation: Users felt more comfortable because they easily located the list contact button because option gives sound when the user slides his finger on the option. While some user needed help when their finger moves fast on the screen they missed the option.

Blind Launcher

Results: Users quickly searched the contact as compare to other applications. 
Observation: User easily performed the task because the contacts are searched by swiping finger top to down(alphabetical order) but in our observation it is time consuming to reach to the desired contact (for example: if contact name starts from 's')

\section{Call Dialer}

The feature is not available.

\section{USER FEEDBACKS}

This study exposes the problems that are faced by most of the blind people in Pakistan while using smart phones. Students at IDA Rieu tackled a number of difficulties while using Smart phones. After the experiment the users give us feedback about the applications. The students who use the Easy Phone for Blinds app give us following feedback:

"I found difficulty in selecting an option but I feel comfortable while composing message"

"I found difficulty in dialing a number because the keypad is not consistent to my phone"

Users also faced difficulty in using Blind Launcher. The students who use the Blind Launcher app said:

"It is easy to use but I am confused while dialing a number. I understand the patterns of number but it will not give any sliding feedback of number while making patterns, only it sounds the number when the number is dialed"

"Simple to use but time consuming in searching an option or contacts from contact list"

One of the teachers at school used Blind Navigator and get very satisfied with this application. She said:

"Give me the name of app so I can suggest my students to use this application in their Android phones"

On other hand another teacher was not comfortable with Blind Navigator and said:

"This application lacks in sliding feedback and it is time consuming"

Many users use Call Dialer some get satisfied with the app but some faced difficulty. Following are the feedbacks for this app:

"It is a simple app but I found difficulty in locating numbers"

"I feel happy while using your app but I am not familiar with mobile phones, due to this I face difficulty in using the app. But I want to learn it in future"

Some user at the school already uses Smart phones. They are not satisfied with the applications. One of the students said:
"We have all features in talk back to use Smart phone we don't need any such kind of application. If you want to make a new application of accessibility then it should support native language.

\section{RESULTS AND DISCUSSION}

H1: Mostly visual impaired people use Symbian phones. The survey results proved the first hypothesis to be true as the $80 \%$ students in the school use Symbian phones with support of talk back. They are not using smart phones due to lack of awareness.

H2: Visually impaired will be more comfortable to use Smart phones with the help of applications than Symbian phones.

This also proved to be true because $65 \%$ students have used comfortably the friendly features of application after demo.

H3: Users will avoid switching to another screen reader and prefer the one they use regularly

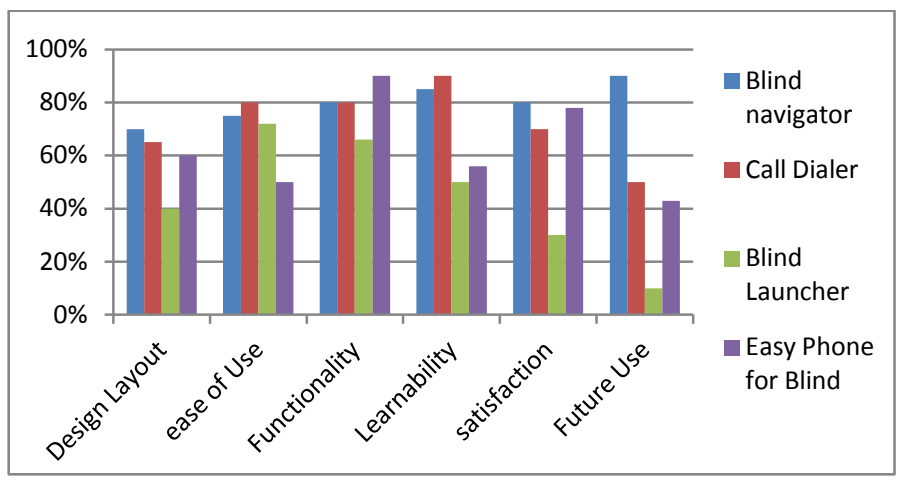

Consequences revealed that the students who use symbian phones are interested in using the smart phone applications but those who have already used smart phones, reluctant to switch on any other application in contrast of talkback which prove our supposition to be true

H4: Such user will face difficulty while reading messages in Pakistan's native language phonetics.

To evaluate this hypothesis, a task was given to read message in phonetic native language used in Pakistan. Results showed that the $70 \%$ users easily understand the message which proves our hypothesis to be false.

H5: Applications will help in increasing number of smart phones users after proper awareness.

$60 \%$ students believed that if someone would guide them properly then they might use the smart phones and to taste the fruits by latest technology. These feedbacks verified our hypothesis to be true 
Table 2 Hypothesis evaluation

\begin{tabular}{|c|c|c|c|c|}
\hline No. & Hypothesis & Survey Question & Response & Conclusion \\
\hline$\bullet$ & $\begin{array}{l}\text { Mostly visual impaired people use } \\
\text { Symbian phones }\end{array}$ & $\begin{array}{l}\text { Q. Which type of cell } \\
\text { phone do you use? }\end{array}$ & $\begin{array}{l}20 \%=\text { Smart phones } \\
80 \%=\text { Symbian }\end{array}$ & $\begin{array}{l}\text { Hypothesis } 1=\text { True. } \\
\text { Most blind people are using } \\
\text { Symbian phones in Pakistan. }\end{array}$ \\
\hline$\cdot$ & $\begin{array}{l}\text { Visually impaired will be more } \\
\text { comfortable to use Smart phones } \\
\text { with the help of applications } \\
\text { than Symbian phones. }\end{array}$ & $\begin{array}{l}\text { Q. What do you } \\
\text { experienced while } \\
\text { using smart phones? } \\
\text { Q2. Which type of } \\
\text { phone you would like } \\
\text { to prefer in future? }\end{array}$ & $\begin{array}{l}65 \%=\text { comfortable } \\
35 \%=\text { uncomfortable } \\
75 \%=\text { smart phones } \\
25 \%=\text { Symbians }\end{array}$ & $\begin{array}{l}\text { Hypothesis } 2=\text { True. } \\
\text { Most people felt comfortable } \\
\text { with it and want to use smart } \\
\text { phones in future. }\end{array}$ \\
\hline$\cdot$ & $\begin{array}{l}\text { Users will avoid switching to } \\
\text { another application and prefer the } \\
\text { one they use regularly }\end{array}$ & $\begin{array}{l}\text { Q. Do you use } \\
\text { applications } \\
\text { specifically made for } \\
\text { blinds? }\end{array}$ & $\begin{array}{l}100 \%=\text { screen readers } \\
0 \%=\text { applications }\end{array}$ & $\begin{array}{l}\text { Hypothesis } 3=\text { True. } \\
\text { Users do not want to switch } \\
\text { screen readers easily. }\end{array}$ \\
\hline$\cdot$ & $\begin{array}{l}\text { Such user will face difficulty } \\
\text { while reading messages in } \\
\text { Pakistan's native language } \\
\text { phonetics. }\end{array}$ & $\begin{array}{l}\text { Q. Is it comfortable to } \\
\text { read messages in } \\
\text { English Language? } \\
\text { A task also has given to } \\
\text { read a message. }\end{array}$ & $\begin{array}{l}30 \%=\text { No } \\
70 \%=\text { Yes }\end{array}$ & $\begin{array}{l}\text { Hypothesis } 4=\text { False. The } \\
\text { users were comfortable with } \\
\text { this. }\end{array}$ \\
\hline$\bullet$ & $\begin{array}{l}\text { Applications will help in } \\
\text { increasing number of smart } \\
\text { phones users after proper } \\
\text { awareness }\end{array}$ & $\begin{array}{l}\text { Q. Do you want to use } \\
\text { smart phones in the } \\
\text { future if proper } \\
\text { awareness is provided? }\end{array}$ & $\begin{array}{l}60 \%=\text { Yes } \\
40 \%=\text { No }\end{array}$ & $\begin{array}{l}\text { Hypothesis 5= True. More } \\
\text { people loved to use such } \\
\text { applications if somebody } \\
\text { guides them properly. }\end{array}$ \\
\hline
\end{tabular}

\section{CONCLUSION}

This evaluation of four application has revealed that these android application are not enough capable to address all accessibility issues. It is found that users are facing complications in understanding the interface because they want to feel what they are doing. Therefore it is recommended to designers to understand the above discussed issues and design more blind-friendly applications to help them participate in the society.

\section{REFERENCES}

[1] Ashraf, Anam, and Arif Raza. "Usability Issues of Smart Phone Applications: For Visually Challenged people.

[2] “Thompson, S., C. J. Johnston, and Martha L. Thurlow. Universal design applied to large scale assessments. Vol. 44.National Center on Educational Outcomes Synthesis Report, 2002."

[3] "Sanchez, Javier, and JoaquínSelva Roca de Togores. 'Designing Mobile Apps for Visually Impaired and Blind Users.'ACHI 2012, the Fifth International Conference on Advances in Computer-Human Interactions. 2012."

[4] Kane, Shaun K., et al. "Freedom to roam: a study of mobile device adoption and accessibility for people with visual and motor disabilities." Proceedings of the 11th international ACM SIGACCESS conference on Computers and accessibility. ACM, 2009

[5] "Mata, Felix, Andres Jaramillo, and Christophe Claramunt. 'A mobile navigation and orientation system for blind users in a metrobus environment.' Web and Wireless Geographical Information Systems. Springer Berlin Heidelberg, 2011. 94-108."

[6] "Jethjarurach, Nitchaya, and YachaiLimpiyakorn. 'Mobile Product Barcode Reader for Thai
Blinds.'Information Science and Applications (ICISA), 2014 International Conference on.IEEE, 2014.”.

[7] "Cesarano, Carmine, Anna Rita Fasolino, and PorfirioTramontana. 'Improving usability of web pages for blinds.'Web Site Evolution, 2007.WSE 2007.9th IEEE International Workshop on.IEEE, 2007."

[8] "Khan, Hamna, MuniraIqbal, and Narmeen Shawoo Bawany. 'Web Accessibility Evaluation of News Websites Using WCAG 2.0.' Research Journal of Recent Sciences ISSN 2277: 2502."

[9] 'Robest, Y. O. N. G. VisionTouchPhone" for the Blind.' The Malaysian journal of medical sciences: MJMS 20.5 (2013): 1."

[10] "Kane, S., J. Bigham, and J. Wobbrock. 'Fully Accessible Touch Screens For The Blind And Visually Impaired.' University of Washington (2011).”

[11] Green, Ravonne A., and Julia Huprich. "Web accessibility and accessibility instruction." Journal of Access Services 6.1-2 (2009): 116-136.

[12] Bray, Marty, et al. "Accessibility of middle schools' web sites for students with disabilities." The Clearing House: A Journal of Educational Strategies, Issues and Ideas 80.4 (2007): 169-178.

[13] Brandenburg, Caitlin, et al. "Mobile computing technology and aphasia: An integrated review of accessibility and potential uses." Aphasiology 27.4 (2013): 444-461

[14] Blind Navigator: http://www.gpstracker.net.in/

[15] Easy Phone for Blind: http://www.gamoon.it/

[16] Blind Launcher: https://github.com/arthurzaczek/ launcherforblind

[17] Call Dialer for Blind: sa111222@gmail.com. 
[18] "Kane, Shaun K., Jacob O. Wobbrock, and Richard E. Ladner. 'Usable gestures for blind people: understanding the preference and performance.' Proceedings of the SIGCHI Conference on Human Factors in Computing Systems.ACM, 2011." "Oliveira, João, et al. 'Blind people and mobile touch-based text-entry: acknowledging the need for different flavors.' The proceedings of the 13th international ACM SIGACCESS conference on Computers and accessibility.ACM, 2011."

[19] Gonçalves, Ramiro, et al. "Accessibility levels of Portuguese enterprise websites: equal opportunities for all?." Behaviour\& Information Technology 31.7 (2012): 659-677

[20] Kelly, Brian, et al. "Accessibility 2.0: Next steps for web accessibility." Journal of access services 6.1-2 (2009): 265-294

[21] Wood, Chantelle, et al. "Why does asking questions change health behaviours? The mediating role of attitude accessibility." Psychology \& health 29.4 (2014).

[22] Ellcessor, Elizabeth. "< ALT="Textbooks">: Web Accessibility Myths as Negotiated Industrial Lore." (2014)

[23] Arrigo, Marco, and Giovanni Ciprì. "Mobile Learning for all." Journal of the Research Center for Educational Technology 6.1 (2010): 94-102.
[24] Bigham, Jeffrey P., et al. "VizWiz::LocateIt-enabling blind people to locate objects in their environment." Computer Vision and Pattern Recognition Workshops (CVPRW), 2010 IEEE Computer Society Conference on.IEEE, 2010

[25] Krajnc, Elmar, et al. A touch sensitive user interface approach on smartphones for visually impaired and blind persons. Springer Berlin Heidelberg, 2011.

[26] Evans-Cowley, Jennifer S. "The accessibility of municipal government websites." Journal of eGovernment 2.2 (2006): 75-90.

[27] Bramley, Tom. "Accessibility, easiness and standards." Educational Research47.2 (2005): 251261.Karampiperis,Pythagoras,and Demetrios Sampson*. "Supporting accessible hypermedia in web-based educational systems: defining an accessibility application profile for learning resources." New review of hypermedia and multimedia 10.2 (2004): 181-197

[28] Freire, et al. Proceeding SIGDOC '07 Proceedings of the 25th annual ACM International conference on Design of communication 2007

[29] Kane, et al. Slide rule: making mobile touch screens accessible to blind people using multi-touch interaction techniques Proceedings of the 10th international ACM SIGACCESS conference on Computers and accessibility 20 